\title{
SOME SHARP INEQUALITIES INVOLVING RECIPROCALS OF THE SEIFFERT AND OTHER MEANS
}

\author{
WEI-DONG JIANG
}

\begin{abstract}
In the paper, by establishing the monotonicity of some functions involving the sine and cosine functions, we find some new sharp inequalities involving the reciprocals of the Seiffert, contra-harmonic, arithmetic, geometric and root-square means of two positive real numbers $a$ and $b$ with $a \neq b$.
\end{abstract}

Mathematics subject classification (2010): Primary 26E60; Secondary 11H60, 26A48, 26D05, 33B10. Keywords and phrases: Inequality, mean, monotonicity, sine, cosine, Seiffert mean.

\section{REFERENCES}

[1] M. Abramowitz And I. A. Stegun (Eds), Handbook of Mathematical Functions with Formulas, Graphs, and Mathematical Tables, National Bureau of Standards, Applied Mathematics Series 55, 4th printing, with corrections, Washington, 1965.

[2] H. AlzER AND S.-L. QIU, Monotonicity theorems and inequalities for complete elliptic integrals, J. Comput. Appl. Math. 172, 2 (2004), 289-312.

[3] G. E. Andrews, R. Askey, And R. Roy, Special Functions, Encyclopedia of Mathematics and its Applications 71, Cambridge University Press, Cambridge, 1999.

[4] Y.-M. ChU, Y.-F. QIU, M.-K. WANG, AND G.-D. WANG, The optimal convex combination bounds of arithmetic and harmonic means for the Seiffert's mean, J. Inequal. Appl. 2010 (2010), Article ID 436457, 7 pages.

[5] H. LiU AND X.-J. Meng, The optimal convex combination bounds for Seiffert's mean, J. Inequal. Appl. 2011 (2011), Article ID 686834, 9 pages.

[6] Y.-M. ChU, M.-K. WAng, AND W.-M. Gong, Two sharp double inequalities for Seiffert mean, J. Inequal. Appl. 2011 (2011), 44, 7 pages.

[7] Y.-M. Chu, C. Zong And G.-D. WANG, Optimal convex combination bounds of Seiffert and geometric means for the arithmetic mean, J. Math. Inequal. 5, 3 (2011), 429-434.

[8] S.-Q. GAO, H.-Y. GAO, AND W.-Y. SHI, Optimal convex combination bounds of the centroidal and harmonic means for the Seiffert mean, Int. J. Pure Appl. Math. 70, 5 (2011), 701-709.

[9] S.-W. Hou AND Y.-M. CHU, Optimal convex combination bounds of root-square and harmonic rootsquare means for Seiffert mean, Int. Math. Forum 6, 57 (2011), 2823-2831.

[10] S.-W. Hou AND Y.-M. CHU, Optimal convex combination bounds of root-square and harmonic rootsquare means for Seiffert mean, Int. J. Math. Anal. 5, 39 (2011), 1897-1904.

[11] H.-J. SEIFFERT, Problem 887, Nieuw Arch. Wiskd. (4) 11, 2 (1993), 176.

[12] E. Neuman And J. SÁndor, On the Schwab-Borchardt mean, Math. Pannon. 14, 2 (2003), 253-266.

[13] H.-J. SEIFFERT, Aufgabe $\beta$ 16, Die Wurzel 29 (1995), 221-222.

[14] H.-J. SEIFFERT, Ungleichungen für einen bestimmten Mittelwert, Nieuw Arch. Wisk. 4, 13 (1995), 195-198.

[15] M.-K. WANG, Y.-F. QIU, AND Y.-M. ChU, Sharp bounds for Seiffert means in terms of Lehmer means, J. Math. Inequal. 4, 4 (2010), 581-586.

[16] C. Zong AND Y.-M. ChU, An inequality among identric, geometric and Seiffert's means, Int. Math. Forum 5, 26 (2010), 1297-1302. 
[17] Y.-M. ChU, M.-K. WAng, S.-L. QIU, AND Y.-F. QIU, Sharp generalized Seiffert mean bounds for Toader mean, Abstr. Appl. Anal. 2011 (2011), Article ID 605259, 8 pages.

[18] Y.-M. CHU, Y.-F. QIU, AND M.-K. WANG, Sharp power mean bounds for the combination of Seiffert and geometric means, Abstract and Applied Analysis, Volume 2010, Article ID 108920, 12 pages, doi: 10. 1155/2010/108920.

[19] W.-D. JiAnG, On an inequality of Seiffert's mean, College Math. 25, 1 (2009), 148-150. (Chinese)

[20] E. NeUmAn AND J. SÁNDOR, On certain new means of two arguments and their extensions, Int. J. Math. Math. Sci. 2003, 16 (2003), 981-993. 